\title{
Synoptic-mesoscale analysis and numerical modeling of a tornado event on 12 February 2010 in northern Greece
}

\author{
I. T. Matsangouras ${ }^{1}$, P. T. Nastos ${ }^{1}$, and I. Pytharoulis ${ }^{2}$ \\ ${ }^{1}$ Laboratory of Climatology and Atmospheric Environment, Faculty of Geology and Geoenvironment, \\ National and Kapodistrian University of Athens, Greece \\ ${ }^{2}$ Department of Meteorology and Climatology, School of Geology, Aristotle University of Thessaloniki, Greece
}

Received: 31 December 2010 - Revised: 30 April 2011 - Accepted: 27 June 2011 - Published: 20 July 2011

\begin{abstract}
Tornadoes are furious convective weather phenomena, with the maximum frequency over Greece during the cold period (autumn, winter).This study analyzes the tornado event that occurred on 12 February 2010 near Vrastama village, at Chalkidiki's prefecture, a non urban area $45 \mathrm{~km}$ southeast of Thessaloniki in northern Greece. The tornado developed approximately between 17:10 and 17:35 UTC and was characterized as F2 (Fujita Scale). The tornado event caused several damages to an industrial building and at several olive-tree farms.

A synoptic survey is presented along with satellite images, radar products and vertical profile of the atmosphere. Additionally, the nonhydrostatic WRF-ARW atmospheric numerical model (version 3.2.0) was utilized in analysis and forecast mode using very high horizontal resolution $(1.333 \mathrm{~km} \times 1.333 \mathrm{~km})$ in order to represent the ambient atmospheric conditions. A comparison of statistical errors between WRF-ARW forecasts and ECMWF analysis is presented, accompanied with LGTS 12:00 UTC soundings (Thessaloniki Airport) and forecast soundings in order to verify the WRF-ARW model. Additionally, a comparison between WRFARW and ECMWF thermodynamic indices is also presented. The WRF-ARW high spatial resolution model appeared to simulate with significant accuracy a severe convective event with a lead period of $18 \mathrm{~h}$.
\end{abstract}

\section{Introduction}

Tornadoes are one of nature's most extreme and violent phenomena with high localized damage potential associated with severe convective storms. Extremely high winds, inside and around the tornado's funnel, are able to cause destruction even in strong buildings and in many cases loss of life. Despite the significant improvement in understanding and forecasting tornadoes (short term), owning to both theoretical insight progress and the use of Doppler Radars (Holum et al., 1997; Bluestein et al., 1997), their small spatial scale and short lifetime seem to be the determinant factors about the various natural mechanisms that produce these intensely swirling air columns (Church et al., 1993). Tornadoes occur in many parts of the world (Fujita, 1973) and several publications during the last two decades indicate their occurrence

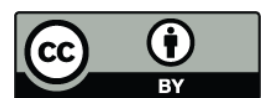

Correspondence to: P. T. Nastos

(nastos@geol.uoa.gr) in many European countries (Dessens, 1984; Dessens and Snow, 1987; Gayá et al., 1997; Paul, 1999; Reynolds, 1999; Dotzek, 2001; Holzer, 2001; Bertato et al., 2003; Dotzek, 2003; Giaiotti et al., 2007; Giaiotti and Stel, 2007).

However, remarkable tornado events in Greece occurred between 1900 and 1999 have been reported only in limited academic research (Livadas, 1954; Kanellopoulou, 1977; Ogden, 1984; Flocas, 1992; Sioutas, 2002; Nastos and Matsangouras, 2010). Matsangouras and Nastos (2010) as well as Matsangouras et al. (2010) focus on exceptional Greek tornado events that took place after 2000, such as the tornado in Athens' international airport "Eleftherios Venizelos" and the one registered in Varda, at Elias prefecture western Greece. In due course, a systematic tornado recording research initiated by the Laboratory of Climatology and Atmospheric Environment (LACAE) of National and Kapodistrian University in Athens (NKUA) 4 yr ago. For academic purposes, an online tornado report system (http://tornado.geol.uoa.gr) was established developing an online tornado database for 


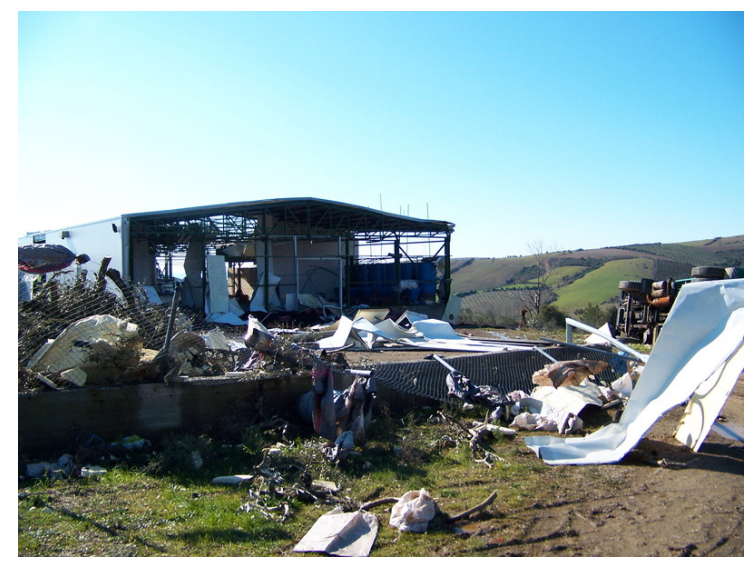

(a)

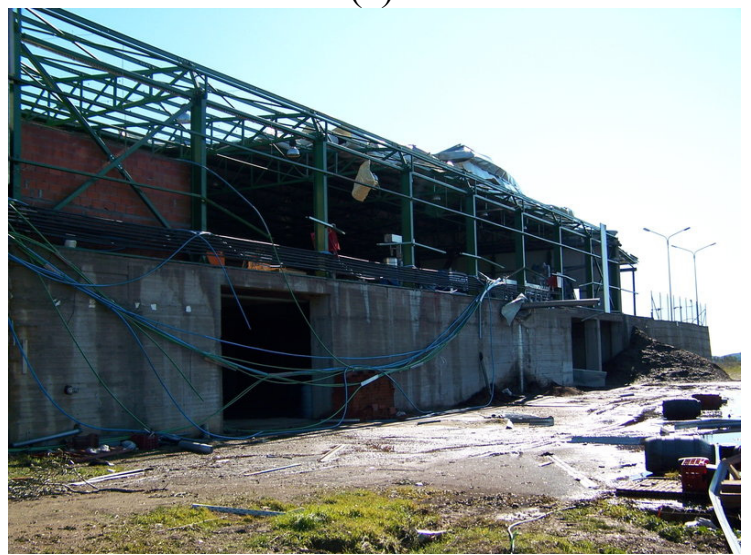

(c)

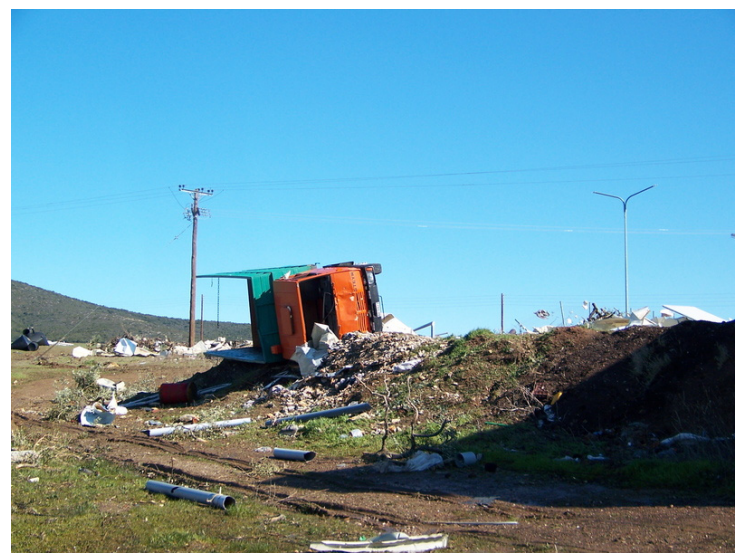

(b)

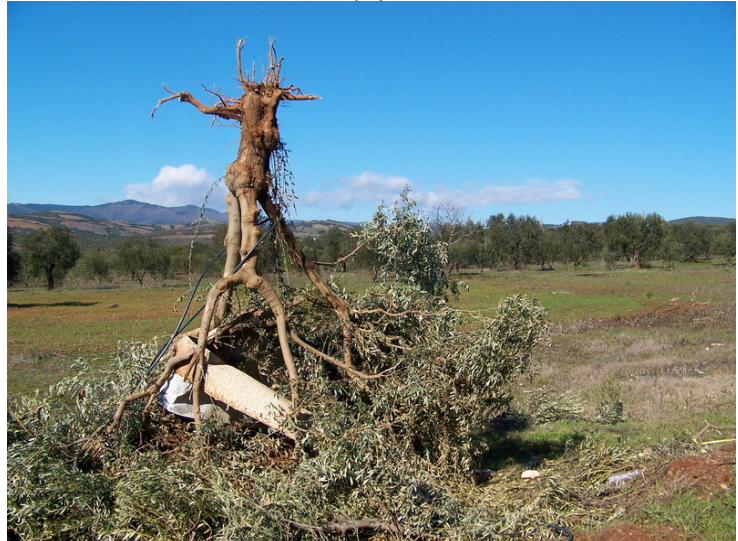

(d)

Figure 1. Tornado's damages near Vrastama Chalkidiki on 12 February 2010

(Photos: http://forum.snowreport.gr/forum_posts.asp?TID=23403\&PN=1).

Greece that records general public data. In this study a thorough analysis of the catastrophic tornado event near Vrastama village of Chalkidiki (Northern Greece) is carried out. It is apparent that this tornado was not the first in history over Greece and definitely it will not be the last one. For the first time in Greece a high spatial WRF-ARW simulation was carried out in order to investigate the capabilities of this NWP model on severe convective events, such as this tornado event.

\section{Tornado survey}

The tornado occurred $2.5 \mathrm{~km}$ south of Chalkidiki's Vrastama village, a non urban area $45 \mathrm{~km}$ southeast of Thessaloniki in northern Greece (Lat: 40.36, Lon: 23.54; Figs. 2d, 4), on 12 February 2010. The system developed approximately between 17:10 and 17:35 UTC, caused significant damages at a green olive processing unit and on several olive oil farms. Based on the caused damages (Fig. 1), it could be characterized at least as an F2 (Fujita scale) or T4-T5 of TORRO scale (Meaden, 1976). The tornado carried away by
200-400 m several metallic parts of the oil processing building while scattered broken branches of olives oil trees were found along the tornado path.

\section{Synoptic survey}

The upper air analyses showed that during the day of the event a closed cyclonic circulation that prevailed at the isobaric level of $500 \mathrm{hPa}$ over central Italy (Fig. 2a) was associated with cold air masses $\left(-35^{\circ} \mathrm{C}\right)$. The closed low induced a SW upper air stream over the area of interest at 12:00 UTC (ECMWF ERA-Interim data used in this study have been obtained from the ECMWF data server). The cyclonic circulation extended throughout the lower troposphere. At Mean Sea-Level (MSL), the low was located over central Adriatic Sea at 12:00 UTC (not shown) and was associated with a cold front (over western Greece) propagating eastwards. At 18:00 UTC the UKMO MSL pressure analysis shows that the cold front extended from northern Greece to Peloponnesus (south Greece) and northern Libya through the area of interest (Fig. 2b). MSG-2 satellite imagery at Ch9 (10.8 $\mu \mathrm{m})$ 


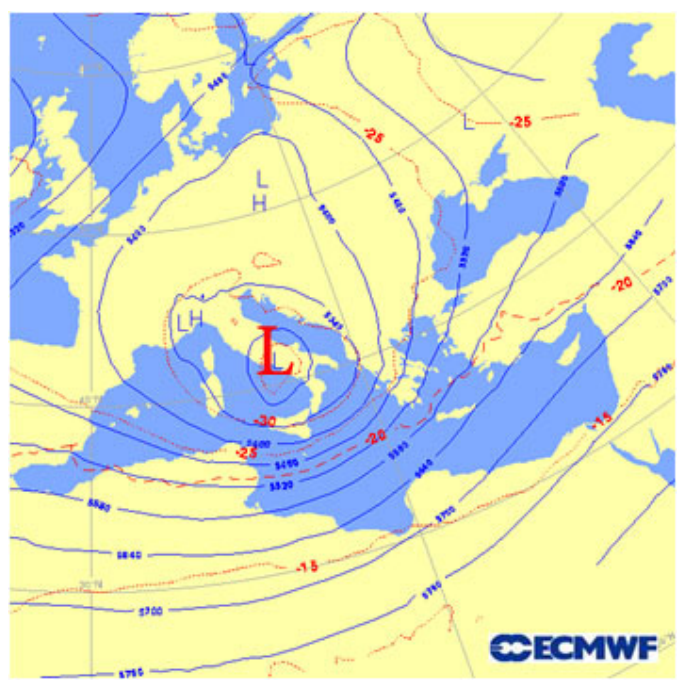

(a)

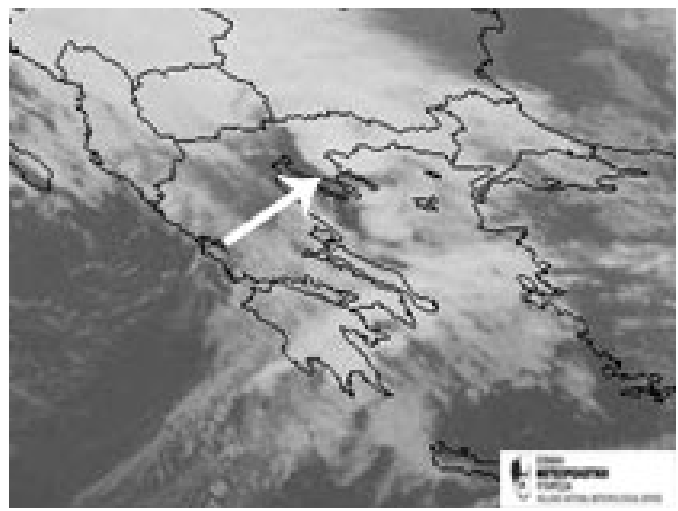

(c)

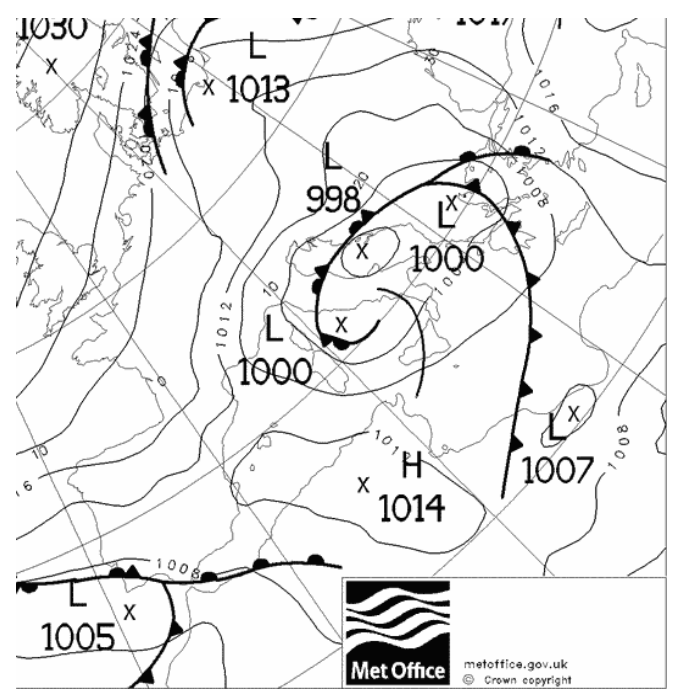

(b)

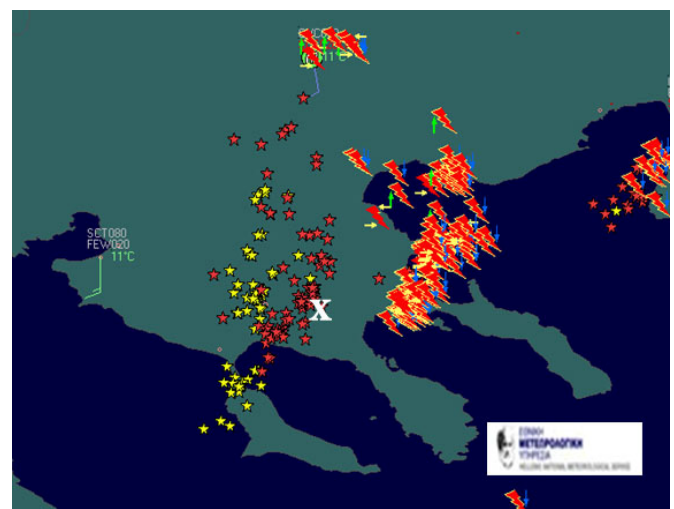

(d)

Figure 2. ECMWF Re-analysis at 12:00 UTC (a), UKMO MSL analysis at 18:00 UTC (b), IR satellite image (Ch9) at 17:30 UTC (white arrow indicates the associated storm) (c) and lightning activity at 17:00 UTC (yellow stars), 17:30 UTC (red stars) and 18:00 UTC (red spikes) from HNMS (d), on 12 February 2010.

revealed convective clouds $(\mathrm{Cb})$ associated with the cold front affecting the area of interest at 17:30 UTC (Fig. 2c). At the time of event, the nearest meteorological station of Thessaloniki-LGTS ( $\sim 45 \mathrm{~km} \mathrm{NW}$ of the event) reported significant weather phenomena such as $\mathrm{Cb}$.

The thermodynamic environment about the closest upper air station (LGTS) at 12:00 UTC ( $\sim 4 \mathrm{~h}$ prior to the event) did not reveal any significant storm index (K Index: $21.6^{\circ} \mathrm{C}$, Showalter Index (SI): $4.52^{\circ} \mathrm{C}$, Severe Weather Threat Index (SWEAT): 69.76, Convective Available Potential Energy (CAPE): $14.12\left(\mathrm{~J} \mathrm{~kg}^{-1}\right)$ and Lifted Index (LIFT): $2.39^{\circ} \mathrm{C}$. Figure $2 \mathrm{~d}$ illustrates the spatiotemporal variability of lightings from 17:00 to 18:00 UTC, which were acquired by Hellenic National Meteorological Service (HNMS) The white " $X$ " denotes the location of the tornado while the yellow stars, the red stars and the red spikes show the lightning at 17:00, 17:30 and 18:00 UTC, respectively.
The images of "Aeolus 13" which is the closest radar of the HNMS Radar Network "Alkioni" depicted the convective cloud system propagating eastwards. Aeolus 13 that is located at LGTS, was established in 1980 and its type is WSR-74S (S Band wavelength $10 \mathrm{~cm}$ ). During 2007 its receiver and software (IRIS) were both upgraded. In Fig. 3 the CAPPI (Constant Altitude Plan Position Indicator) at $1 \mathrm{~km}$ height (Fig. 3a-c) and MAX (MAXimum Reflectivity) products (Fig. $3 \mathrm{~d}-\mathrm{f}$ ) are presented in a $15 \mathrm{~min}$ time step. At 17:30 UTC maximum reflectivities of 44-50 dbz appeared in the area of interest.

\section{WRF numerical model simulation}

The WRF-ARW V3.2.0 nonhydrostatic numerical model (Skamarock et al., 2008; Wang et al., 2010) was used in order to simulate the weather conditions at 12 February 2010. Three 2-way interactive nested domains were 


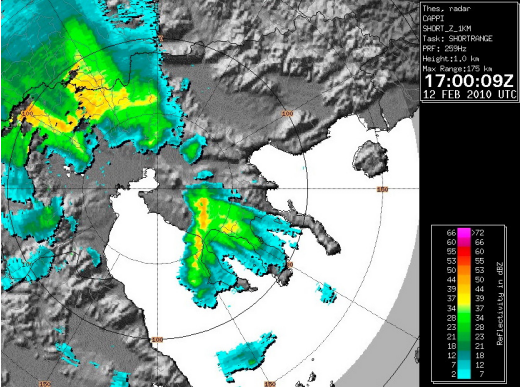

(a)

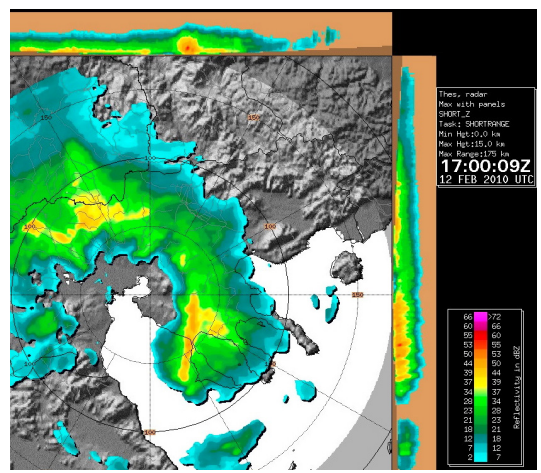

(d)

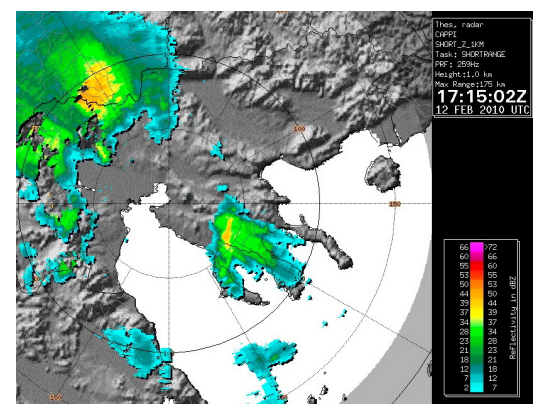

(b)

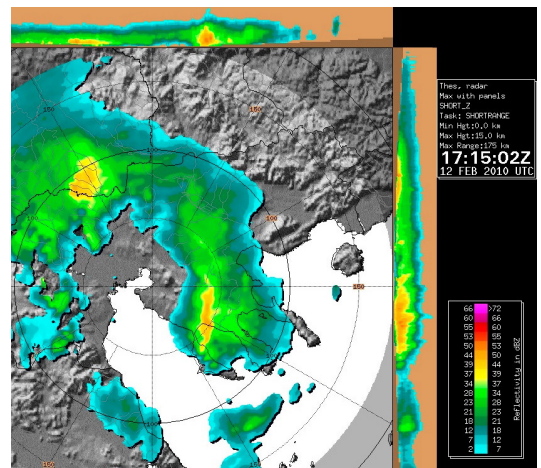

(e)

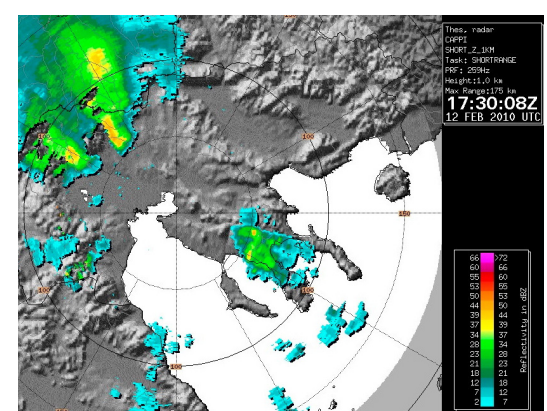

(c)

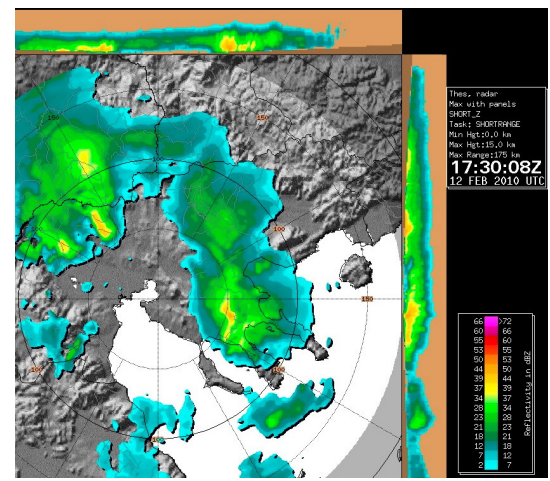

(f)

Figure 3. Radar images from LGTS Radar: CAPPI at $1 \mathrm{~km}$ height in $15 \mathrm{~min}$ time step (a-c) and MAX (MAXimum Reflectivity) in 15 min time step (e-f).
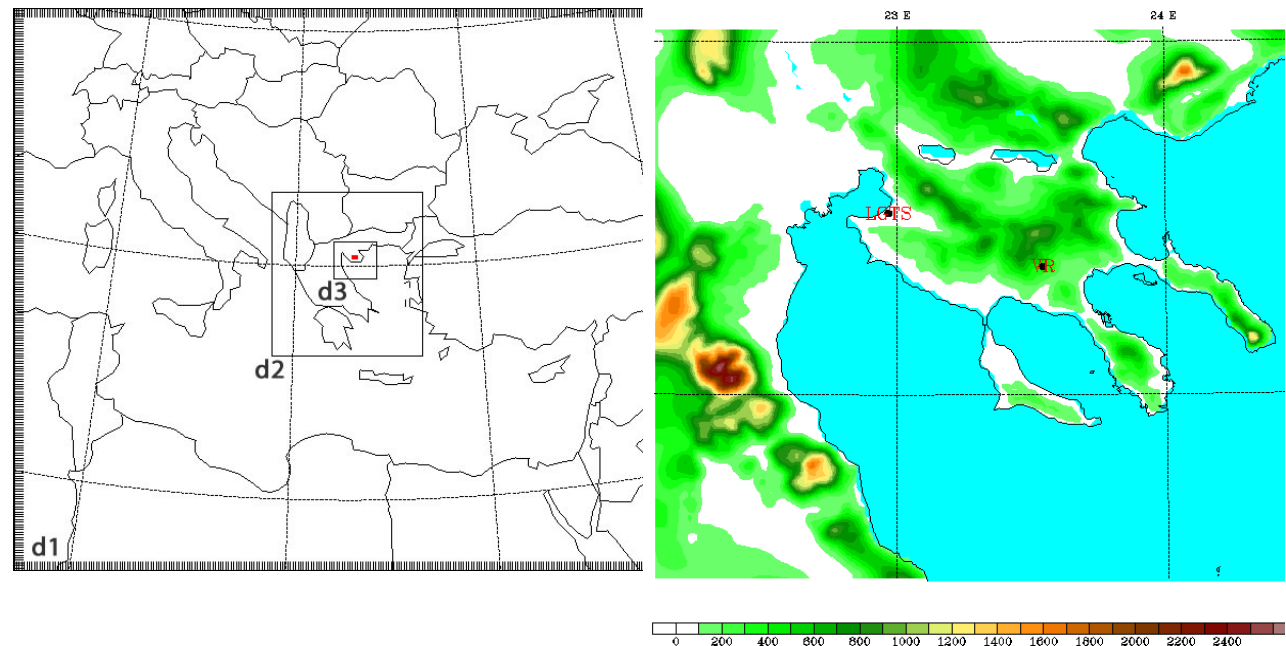

Figure 4. The three domains (D1-D2-D3) of WRF runs (the red spot indicates the tornado event area) (a) and the topography (m) of domain D3 (b); LGTS is the airport of Thessaloniki and VR stands for Vrastama.

utilized (Fig. 4a). The spatial resolution of the model was $12 \mathrm{~km}$ for D1 (over central and eastern Mediterranean Sea), $4 \mathrm{~km}$ for D2 (over Greece) and $1.333 \mathrm{~km}$ for D3 (over northern Greece-Chalkidiki; Fig. 4b). The runs started at $00 \mathrm{Z}$ on 12 February 2010 and the forecast horizon was $24 \mathrm{~h}$.
The ECMWF analysis and 3-hourly forecasts of the 00:00 UTC cycle of 12 February 2010 with a spatial resolution of $0.125 \times 0.125$ degrees were used as initial and lateral boundary conditions, respectively, for the domain D1. The seasurface temperatures were also derived from the ECMWF 


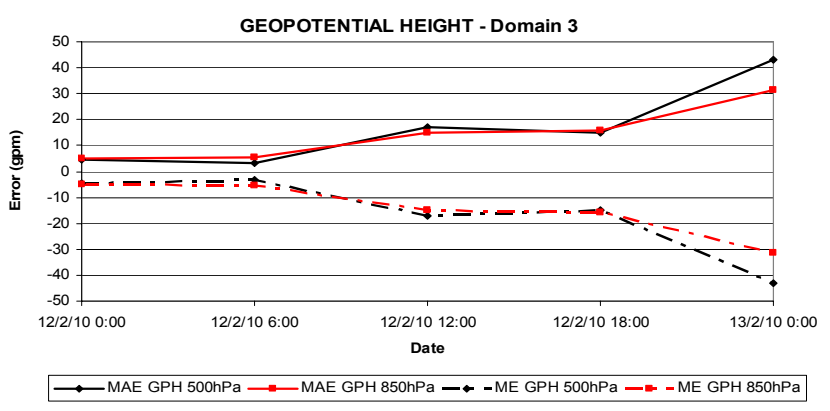

(a)

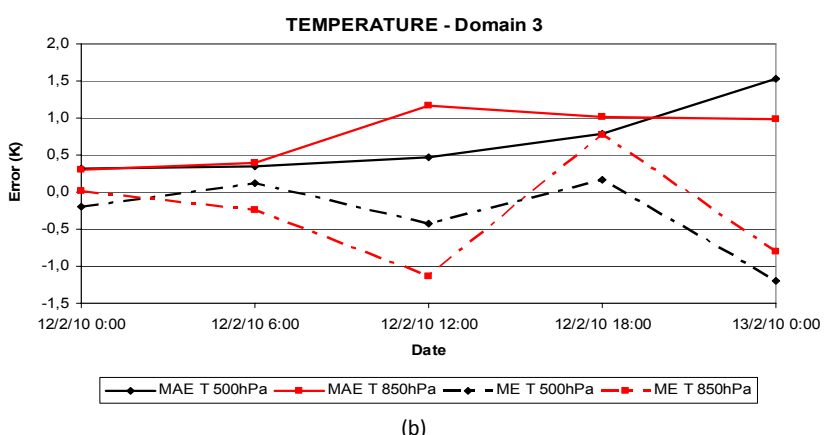

Figure 5. All statistics (Mean Absolute Error - MAE and Mean Error - ME) were calculated in the inner domain (D3) through the comparison of ECMWF gridded analyses and WRF forecasts for Geopotential Height at 500 and $850 \mathrm{hPa}$ (a) and for temperature at 500 and $850 \mathrm{hPa}(\mathbf{b})$.

analysis and were kept fixed to their initial values throughout the simulations. In the vertical, 39 sigma levels (up to $50 \mathrm{hPa}$ ) with increased resolution in the boundary layer were used by all nests. The GFDL scheme, the MoninObukhov (Eta), the Mellor-Yamada-Janjic level 2.5 and the NOAH Unified model were used in all nests to represent longwave/shortwave radiation, surface layer, boundary layer and soil physics, respectively. Cumulus convection was parameterized only in nests D1 and D2 by the Kain-Fritsch (new Eta) scheme. The Ferrier (new Eta) microphysical scheme is used by several operational NWP models as SKIRON, Eta, WRF-NMM and for this reason we stacked to this microphysical scheme to simulate our case study.

\section{Results and discussion}

With continuously improving computer technology, highresolution model simulations can be conducted to study severe weather phenomena such as tornadoes in order to determine how far in advance these processes can be predicted. In our case study a tornado formed near Vrastama village, (Chalkidiki's prefecture) in northern Greece, between 17:10-17:30 UTC on 12 February 2010. The tornado intensity could be characterized as F2 (Fujita scale) based on the significant damages. The tornado formation was associ-

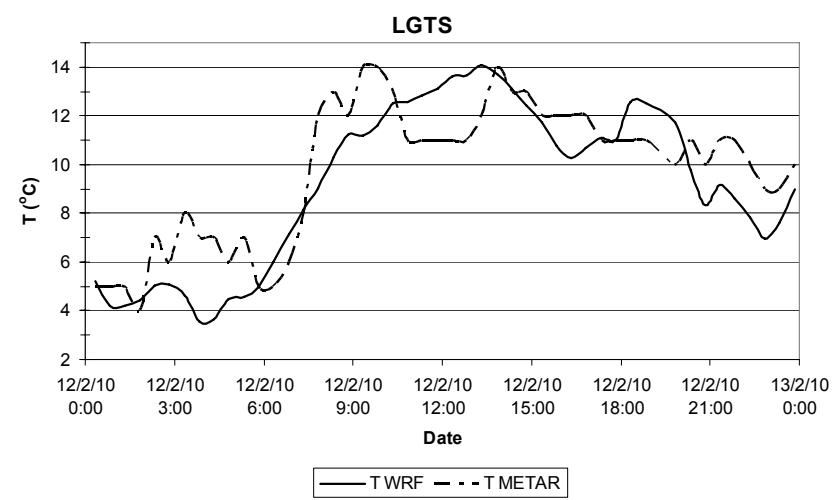

(a)

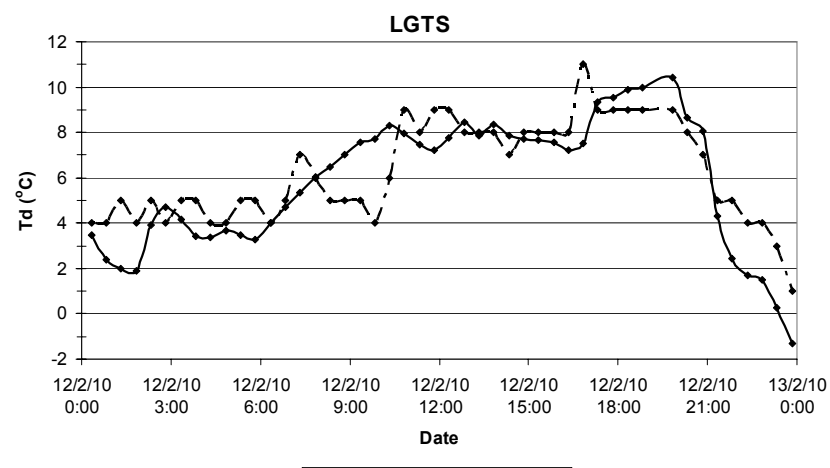

(b)

Figure 6. Time series of (a) Temperature and (b) Dew-point Temperature observations (METAR) and WRF forecasts at LGTS (Time in UTC).

ated with the passage of a cold front propagating eastwardnortheastward.

In order to evaluate the WRF forecasts we proceed through the comparison of ECMWF gridded analyses and WRF forecasts. All statistics (Mean Absolute Error - MAE and Mean Error - ME) were calculated in the inner domain (D3) for Geopotential Height of $500 \mathrm{hPa}$ and $850 \mathrm{hPa}$, as well as the temperature for these levels (Fig. 5). The WRF forecasts were interpolated at the locations of ECMWF data $(0.125 \times 0.125 \mathrm{deg}$. $)$ and all statistics were resulted from a total of 234 pairs of forecast/analysis at each time. The WRF underestimated ( $\sim 15 \mathrm{gpm})$ the Geopotential Height $(\mathrm{GH})$ at 500 and $850 \mathrm{hPa}$ after 06:00 UTC (thus predicting a deeper approaching through), but did very well for both temperatures $(T)$ at 500 and $850 \mathrm{hPa}$ at 18:00 UTC.

Additionally to GH-T comparison of middle and lower atmosphere, we calculated the statistics (Mean Error, Mean Absolute Error and Root Mean Square Error) of Temperature $(T)$ and Dew-Point Temperature $\left(T_{\mathrm{d}}\right)$ at LGTS on 12 February 2010 (Fig. 6). The LGTS is the closest ( $45 \mathrm{~km}$ ) meteorological station of HNMS Meteorological Station Network. The statistics were derived from a total of 47 pairs of Metar 
Table 1. Statistics (Mean Error, Mean Absolute Error and Root Mean Square Error) of Temperature $(T)$ and Dew-Point Temperature $\left(T_{\mathrm{d}}\right)$ at LGTS on 12 Feb 2010. Negative values of Mean Error indicate underestimation by WRF.

\begin{tabular}{cccc}
\hline & Mean Error & Mean Absolute Error & Root Mean Square Error \\
\hline$T$ & -0.61 & 1.50 & 1.78 \\
$T_{\mathrm{d}}$ & -0.41 & 1.28 & 1.59 \\
\hline
\end{tabular}

Observations and WRF forecasts at LGTS. The WRF output Temperature $(T)$ after 06:00 UTC overestimated the real temperature and $3 \mathrm{~h}$ later underestimated it until 12:00 UTC. After this time it followed too close the real temperature. On the other hand, the Dew-Point Temperature $\left(T_{\mathrm{d}}\right)$ after 12:00 UTC did pretty well with the real Dew-Point Temperature. In sum the Temperature $(T)$ was underestimated by WRF with a mean error of 0.6181 and Dew-Point $\left(T_{\mathrm{d}}\right)$ was also underestimated with a mean error of 0.4188 (Table 1). The statistical scores of temperature and dew-point temperature at the airport of Thessaloniki (LGTS) are lower than those exhibited by the statistical evaluation of modern high resolution NWP models in Greece. Gofa et al. (2008) evaluated the operational SKIRON $\left(0.06^{\circ} \times 0.06^{\circ}\right)$ and COSMOGR $\left(0.0625^{\circ} \times 0.0625^{\circ}\right)$ forecasts produced by HNMS at 30 Greek stations (including LGTS) in 2007. They found RMSE between $1.9-2.5^{\circ} \mathrm{C}$ for temperature and $2.3-3.3^{\circ} \mathrm{C}$ for dew-point temperature in the first 24 forecast hours. Certainly, one must keep in mind that the scores of our study (a) correspond to a single high-impact weather event at one station and not to a long period with different weather types at several stations and (b) are based on METAR observations in which the temperatures are rounded to the nearest integer (introducing a maximum error of $\pm 0.5^{\circ} \mathrm{C}$ ).

Moreover, we carried out a verification of Vertical profiles of predicted Temperature ( $T$ WRF), observed Temperature ( $T$ sounding), predicted Dew-Point Temperature $\left(T_{\mathrm{d}}\right.$ WRF) and observed Dew-Point Temperature ( $T_{\mathrm{d}}$ sounding) at LGTS on 12:00 UTC 12/02/10 (not shown). The predicted vertical profile of $T$ ( $T$ WRF) was identical with the observed Temperature ( $T$ Sounding). The predicted $T_{\mathrm{d}}$ vertical profile was identical with the observed $T_{\mathrm{d}}$ ( $T_{\mathrm{d}}$ Sounding) up to $600 \mathrm{hPa}$. Futher higher a predicted $T_{\mathrm{d}}$ was ranged $\pm 10^{\circ} \mathrm{C}$ from the observed $T_{\mathrm{d}}$.

Lift Index, $\mathrm{K}$ Index and others thermodynamic indices were calculated for tornado's spot at 18:00 UTC. The indices were based on ECMWF analyses and WRF $18 \mathrm{~h}$ forecasts and carried through the RIP software calculations. The $18 \mathrm{~h}$ predicted indices via WRF were too close with the ECMWF analysis indices (Table 2) revealing conditions for convective event. In addition to the above predicted thermodynamic indices, the WRF-ARW model revealed the Bulk Richardson Number Shear (BRNSHR) over the area of interest with maximum values of $300-400 \mathrm{~m}^{2} \mathrm{~s}^{-2}$ at 17:30 UTC (Fig. 7a). The Energy Helicity Index (EHI) that combines he-
Table 2. Thermodynamic indices for Vrastama tornado's formation point at 18:00 UTC of 12/2/2010, calculated by RIP software. LI is lifted index, K is K-index, TT is Total Totals Index, SWI is Showalter Index, CAPE is Convective Available Potential Energy $\left(\mathrm{J} \mathrm{kg}^{-1}\right)$, SWEAT Sweat Index.

\begin{tabular}{lcc}
\hline Index & ECMWF & WRF \\
\hline LI & -1.4 & -2.7 \\
K & 30 & 34 \\
TT & 57 & 58 \\
SWI & -0.5 & -1.8 \\
CAPE & 254 & 545 \\
SWEAT & 416 & 537 \\
\hline
\end{tabular}

licity and instability into one number was also was depicted at 17:30 UTC over the area of tornado formation (Fig. 7b) as the storm was approaching. Similar conclusions are drawn from the investigation of the following forecasts products: the Storm-Relative Environmental Helicity (SREH, Sfc $3 \mathrm{~km}$ ) in Fig. 7c and Vorticity Generation Potential (VGP) in Fig. 7d.

It is worth to mention that the WRF forecasts products of maximum reflectivity predicted for 17:40 UTC and 17:50 UTC values equal to 49.5 and $52 \mathrm{dBz}$ respectively. These values are in agreement with the RADAR products with an offset of $10 \mathrm{~min}$ (MAX reflectivity $44-50 \mathrm{dBz}$ ).

It is apparent that the analysis described in this paper is based on a single case study, therefore it may not be appropriate to generalize the results obtained by the WRF-ARW. An ambitious project is in progress by the authors in order to present a thermodynamic climatology of indices for tornado formation over specific sub regions of Greece. However, this case study demonstrates the usability and capability of high resolution WRF-ARW model in simulating severe convective events with a lead period of $18 \mathrm{~h}$. 


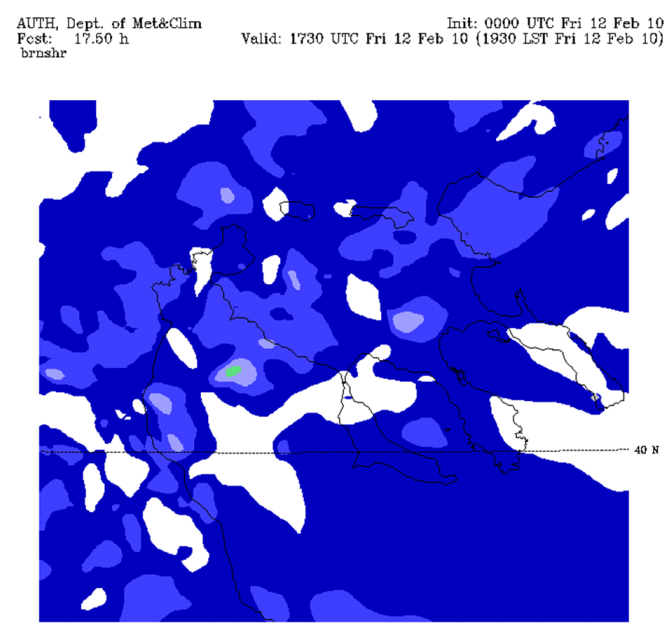

(a)
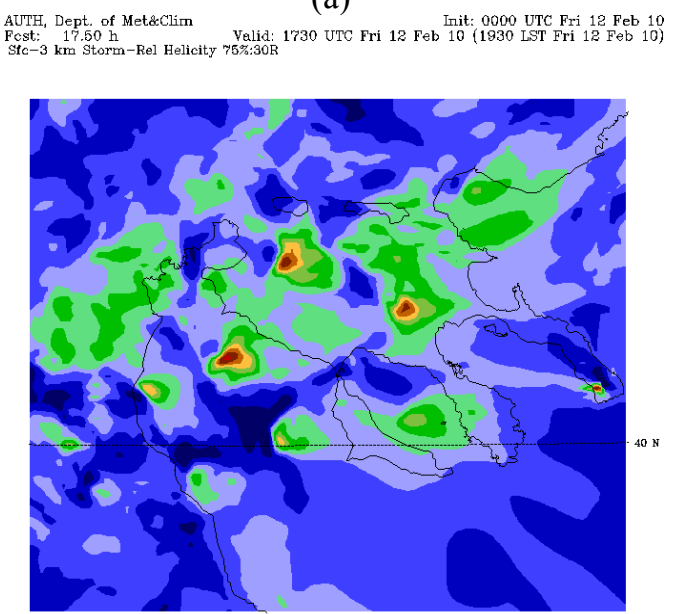

$(\mathrm{c})$

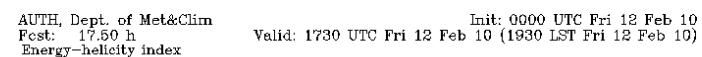

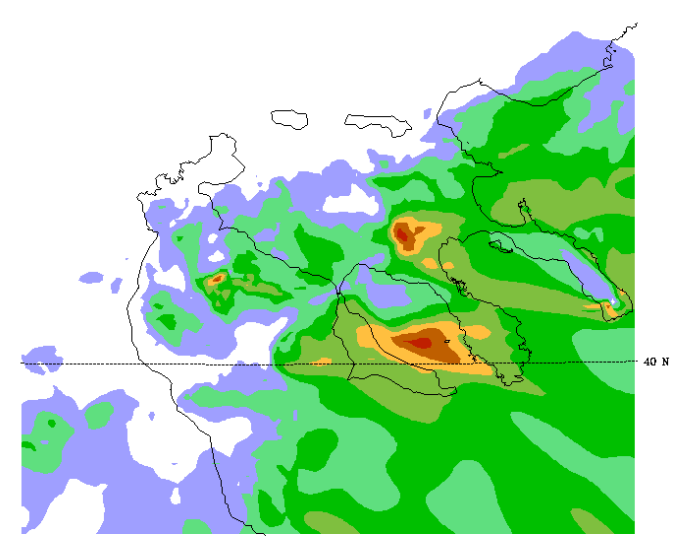

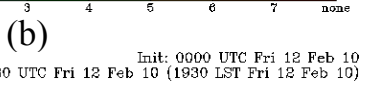

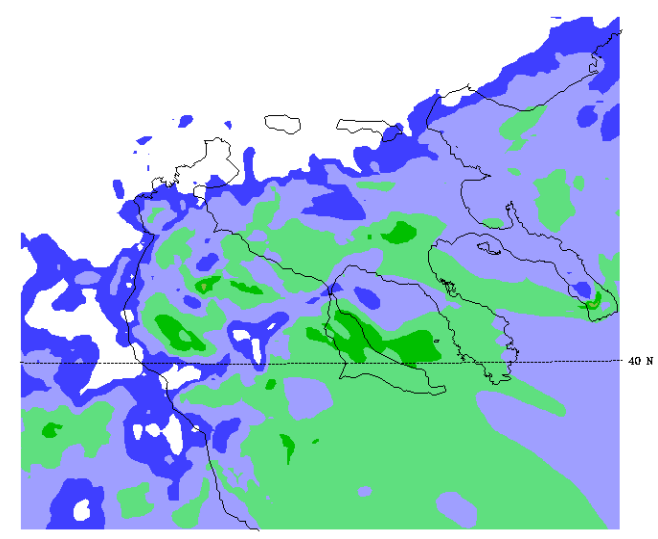

(d)

Figure 7. WRF-ARW outputs based on Ferrier microphysics scheme at 17:30 UTC on 12 February 2010. Bulk Richardson Number Shear $\left(\mathrm{m}^{2} \mathrm{~s}^{-2}\right)(\mathbf{a})$, Energy Helicity Index (b), Storm-Relative Environmental Helicity $\left(\mathrm{m}^{2} \mathrm{~s}^{-2}\right)$ (c) and Vorticity Generation Potential $\left(\mathrm{m} \mathrm{s} \mathrm{s}^{-2}\right)(\mathbf{d})$. Calculated using the RIP software.

Acknowledgements. The authors would like to acknowledge ECMWF, Eumetsat, MetOffice, HNMS for the processed data that were used in order to complete this study and NCAR for providing the WRF-ARW model. Pictures of the tornado provided by http://forum.snowreport.gr/ are thankfully acknowledged. Also authors need to express their thanks to the anonymous who reported the tornado event to our online reporting system http://tornado.geol.uoa.gr.

\section{Edited by: F. Stel}

Reviewed by: three anonymous referees

\section{SC 1 The publication of this article is sponsored by the Swiss Academy of Sciences.}

\section{References}

Bertato, M., Giaiotti, D. B., Manzato, A., and Stel, F.: An interesting case of tornado in Friuli-Norteastern Italy, Atmos. Res., 67-68, 3-21, 2003.

Bluestein, H. B., Wesley, P. U., Dowell, D. C., Hutchinson, T. A., Crawford, T. M., and Wood, A. C.: Doppler radar analysis of the Northfield, Texas, tornado of 25 May 1994, J. Appl. Meteorol., 125, 212-230, 1997

Church, C. R., Burgess, D., Doswell, C., and Davis-Jones, R. P. (Eds.): The Tornado: Its Structure, Dynamics, Prediction and Hazards, Geophys. Monogr., Vol. 79, American Geophysical Union, Washington DC, 637 pp., 1993.

Dessens, J.: Les Trombes en France. Climatologie et Caracteristiques Physiques, Lannemezan, France, 1984. 
Dessens, J. and Snow, J. T .: Tornadoes in France, Weather Forecast., 4, 110-132, 1987.

Dotzek, N.: Tornadoes in Germany, Atmos. Res., 56, 233-251, 2001.

Dotzek, N.: An updated estimate of tornado occurrence in Europe, Atmos. Res., 67-68, 153-161, 2003.

Fujita, T. T.: Tornadoes around the world, Weatherwise, 26, 56-62, 1973.

Flocas, A. A.: Lessons of Meteorology and Climatology, 296-299, 1992 (in Greek).

Gayá, M., Ramis, C., Romero, R., and Doswell III, C. A.: Tornadoes in the Balearic Islands (Spain): Meteorological setting, Proceedings, INM/MO International Symposium on Cyclones and Hazardous Weather in the Mediterranean (Palma de Mallorca, Spain), Universitat de les Isles Baleares, 525-534, 1997.

Giaiotti, D. B. and Stel, F.: A multiscale observational case study of an isolated tornadic supercell, Atmos. Res., 83(2-4), 152-161, 2007.

Giaiotti, D. B., Giovannoni, M., Pucillo, A., and Stel, F.: The climatology of tornadoes and waterspouts in Italy, Atmos. Res., 83, 534-541, 2007.

Gofa, F., Pytharoulis, I., Andreadis, T., Papageorgiou, I., Fragkouli, P., Louka, P., Evgoustoglou, E., and Tyrli, V.: Evaluation of the operational NWP forecasts of the Hellenic National Meteorological Service, Proceedings of the 9th Conference on Meteorology, Climatology and Atmospheric Physics, 28-31 May, Thessaloniki, 51-58, 2008.

Holzer, A. M.: Tornado climatology of Austria, Atmos. Res., 56, 203-211, 2001.

Holum, D. K., Riordan, A. J., Monahan, J., and Keeter, K. K.: Severe thunderstorm and tornado warnings at Raleigh, North Carolina, B. Am. Meteorol. Soc., 78(11), 2559-2575, 1997.

Kanellopoulou, H.: The waterspout of 1st September 1973 in Corfu, Bull. Greek Met. Soc., 5(5), 41-50, 1977 (in Greek).
Livadas, G.: Fish rain in western Macedonia, Meteorologika, No. 2, Publ. Met. Inst. Univ. Thess., Thessaloniki, Greece, 1954.

Matsangouras, J. T. and Nastos, P. T.: The 27 July 2002 tornado event in Athens, Greece, Adv. Sci. Res., 4, 9-13, doi:10.5194/asr-4-9-2010, 2010.

Matsangouras, J. T., Nastos, P. T., and Nikolakis, D. J.: Study of meteorological conditions related to the tornado activity on 253-2009 over NW Peloponnesus, Greece, Proceedings of 10th COMECAP, 25-38 May, Patras, Greece, 417-425, 2010 (in Greek).

Meaden, G. T.: Tornadoes in Britain: their intensities and distribution in space and time, J. Meteorol., 1, 242-251, 1976.

Nastos, P. T. and Matsangouras, J. T.: Tornado activity in Greece within the 20th century, Adv. Geosci., 26, 49-51, doi:10.5194/adgeo-26-49-2010, 2010.

Ogden, D.: Account of the Corfu waterspout 16 June 1983, J. Meteorol., 9(91), 214-215, 1984.

Paul, J. F.: An inventory of tornadoes in France, Weather, 54, 217 219, 1999.

Reynolds, D. J.: European tornado climatology 1960-1989, J. Meteorol., 24, 376-403, 1999.

Sioutas, M. V.: TORRO Tornado Report for Greece, December 2001: a T5-6 tornado at Lassi on 16th, J. Meteorol., 27(270), 207-208, 2002.

Skamarock, W. C., Klemp, J. B., Dudhia, J., Gill, D. O., Barker, D. M., Duda, M. G., Huang, X.-Y., Wang, W., and Powers, J. G.: A description of the Advanced Research WRF Version 3. NCAR/TN-475, 2008.

Wang, W., Bruyère, C., Duda, M., Dudhia, J., Gill, D., Lin, H.C., Michalakes, J., Rizvi, S., Zhang, X., Beezley, J., Coen, J., and Mandel, J.: ARW Version 3 Modeling System User's Guide, NCAR-MMM, 352 pp., 2010. 